\title{
Evaluating mental health service use during and after emergency department visits in a multisite cohort of Canadian children and youth
}

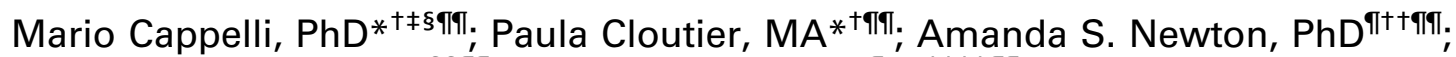

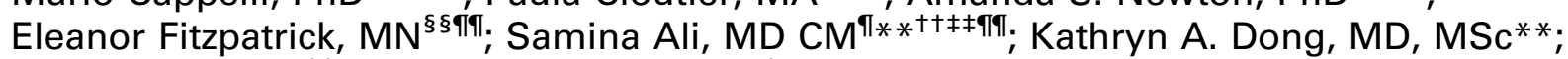 \\ Clare Gray, MD* ${ }^{+\ddagger}$; Allison Kennedy, $\mathrm{PhD}^{* \dagger}$; John S. Lyons, PhD****; Christine Polihronis, $\mathrm{PhD}^{\dagger+\dagger}$;

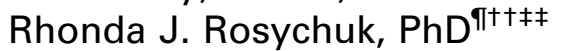

\section{ABSTRACT}

Objectives: The goal of this study was to examine the mental health needs of children and youth who present to the emergency department (ED) for mental health care and to describe the type of, and satisfaction with, follow-up mental health services accessed.

Methods: A 6-month to 1.5-year prospective cohort study was conducted in three Canadian pediatric EDs and one general ED, with a 1-month follow-up post-ED discharge. Measures included 1) clinician rating of mental health needs, 2) patient and caregiver self-reports of follow-up services, and 3) interviews regarding follow-up satisfaction. Data analysis included descriptive statistics and the Fisher's exact test to compare sites.

Results: The cohort consisted of 373 children and youth $(61.1 \%$ female; mean age 15.1 years, 1.5 standard deviation). The main reason for ED presentations was a mental health crisis. The three most frequent areas of need requiring action were mood (43.8\%), suicide risk $(37.4 \%)$, and parent-child relational problems $(34.6 \%)$. During the ED visit, $21.6 \%$ of patients received medical clearance, $40.9 \%$ received a psychiatric consult, and $19.4 \%$ were admitted to inpatient psychiatric care. At the 1-month post-ED visit, $84.3 \%$ of patients/caregivers received mental health follow-up. Ratings of service recommendations were generally positive, as $60.9 \%$ of patients obtained the recommended follow-up care and $13.9 \%$ were wait-listed.

Conclusions: Children and youth and their families presenting to the ED with mental health needs had substantial clinical morbidity, were connected with services, were satisfied with their ED visit, and accessed follow-up care within 1-month with some variability.

\section{RÉSUMÉ}

Objectifs: L'étude visait à examiner les besoins, en santé mentale, de jeunes et d'enfants ayant consulté au service des urgences (SU) pour des troubles de santé mentale, et à décrire le type de suivi assuré par les services de santé mentale et le degré de satisfaction des participants.

Méthode: Une étude de cohorte prospective, d'une durée de 6 mois à 18 mois, y compris 1 mois de suivi après le congé du $\mathrm{SU}$, a été menée dans trois SU pédiatriques et un SU générales, au Canada. Les mesures comprenaient a) l'évaluation des besoins en santé mentale par le clinicien; b) l'appréciation des services de suivi par les patients et les aidants; et c) les entretiens sur le degré de satisfaction des participants quant au suivi. L'analyse des données comprenait des statistiques descriptives ainsi qu'un test selon la méthode exacte de Fisher pour permettre une comparaison entre les centres.

Résultats: La cohorte se composait de 373 jeunes et enfants (filles : 61,1\%; âge moyen : 15,1 ans; écart-type : 1,5). Le principal motif de consultation au SU était un trouble de santé mentale qui avait évolué en crise. Les trois principaux types de besoins nécessitant des interventions étaient des troubles de I'humeur $(43,8 \%)$, le risque de suicide $(37,4 \%)$ et des problèmes de relations entre parents et enfants (34,6\%). Durant les consultations au SU, 21,6 \% des patients ont reçu leur congé après autorisation médicale; $40,9 \%$ ont obtenu une consultation en psychiatrie et $19,4 \%$ ont été hospitalisés au service de psychiatrie. Un mois après la consultation au SU, 84,3\% des patients ou des aidants ont été joints pour un suivi en santé mentale. Dans l'ensemble, l'évaluation des recommandations concernant les services était bonne; $60,9 \%$ des patients avaient obtenu les soins de suivi recommandés et $13,9 \%$ des patients étaient inscrits sur une liste d'attente.

From the ${ }^{*}$ Children's Hospital of Eastern Ontario, Ottawa, ON; †Children’s Hospital of Eastern Ontario Research Institute, Ottawa, ON; $¥ D e p a r t-$ ment of Psychiatry; §School of Psychology, University of Ottawa, Ottawa, ON; Departments of; đPediatrics; ${ }^{* *}$ Emergency Medicine; ††Faculty of Medicine and Dentistry, University of Alberta, Edmonton, AB; ¥¥Women and Children's Health Research Institute, Edmonton, AB; §§IWK Health Centre, Emergency Department; ITPediatric Emergency Research Canada (PERC); ***University of Chicago, Chapin Hall, Chicago, IL; and †††Department of Psychology, Carleton University, Ottawa, ON, Psychology

Correspondence to: Dr. Mario Cappelli, Children's Hospital of Eastern Ontario Research Institute, 401 Smyth Road, Ottawa, ON K1H 8L1; Email: mcappelli@cheo.on.ca 
Conclusions: Les jeunes et les enfants ainsi que les membres de leur famille ayant consulté au SU pour des troubles de santé mentale présentaient des signes cliniques importants de morbidité, ont été mis en lien avec des services, se sont montrés satisfaits de la consultation au SU et ont obtenu, à divers degrés, des soins de suivi au bout de 1 mois.

Keywords: mental health, service use, child, adolescent, emergency department

\section{INTRODUCTION}

Across Canada and the United States, an increasing number of children and youth seek care for mental health $(\mathrm{MH})$ crises in the emergency department (ED). ${ }^{1-5}$ EDs are often the first point of contact between children, youth, their families, and the $\mathrm{MH}$ system, ${ }^{6-9}$ where approximately $50 \%$ of children and youth in Ontario sought care for $\mathrm{MH}$ in the ED because they lacked an outpatient provider. ${ }^{8,9}$ To date, limited research has examined the clinical management and care received in the ED and the associated outcomes. ${ }^{10-12}$ Models of care for pediatric MH emergencies are few, ${ }^{10,11,13}$ clinical practice guidelines for general clinical management do not exist, and, subsequently, the range of emergency $\mathrm{MH}$ services that are provided during the visit varies considerably. ${ }^{13}$

The decision to admit or discharge a child following a $\mathrm{MH}$ crisis and the recommendations associated with this decision are of utmost importance. Most children and youth presenting to the ED with a $\mathrm{MH}$ emergency are discharged home. ${ }^{4,14-19}$ Research suggests that $32 \%$ to $48 \%$ of youth do not receive discharge instructions, ${ }^{11,20}$ and between $21 \%$ and $46 \%$ of patients return to the ED after their initial visit for additional crisis care, ${ }^{21-24}$ which is not always due to increasing clinical acuity. ${ }^{25}$ Furthermore, many discharged youth do not receive urgent outpatient $\mathrm{MH}$ care or physician-based outpatient care within 60 days following their ED visit. $^{23,26}$ Among specific high-risk clinical presentations of suicidal behaviour (ideation, self-harm, or overdose), patients are 5.8 times at risk for suicide mortality after discharge compared to non-suicidal behaviour presentations. ${ }^{27}$

Despite the commonality of discharge following ED pediatric $\mathrm{MH}$ care and the known importance of the recommendations that accompany this disposition decision, little is known about post discharge health care access. Objectives were to identify pediatric $\mathrm{MH}$ needs at the time of ED presentation, variation between sites in terms of patient needs, and the follow-up $\mathrm{MH}$ services accessed by children and their families.

\section{METHODS}

This prospective cohort study was conducted in three Canadian pediatric EDs and one general ED with a pediatric $\mathrm{MH}$ team, with a 1-month follow-up post discharge. The sites consisted of the Children's Hospital of Eastern Ontario (CHEO; Ottawa, ON), IWK Health Centre (IWK; Halifax, NS), Stollery Children's Hospital (SCH; Edmonton, $\mathrm{AB}$ ), and the Royal Alexandra Hospital (RAH; Edmonton, AB). The EDs differed on $\mathrm{MH}$ censuses $(\mathrm{CHEO}=1,512$; $\mathrm{IWK}=853$; $\mathrm{SCH}=431$; $\mathrm{RAH}=953$ ) and $\mathrm{MH}$ care providers (e.g., nurses, emergentologists, psychologists, social workers, psychiatrists). The study was conducted between June 2010 and September 2011. Research assistants (RAs) were available during weekday shifts, Monday to Friday, 0800 to 2300 hours, with some variability. Research ethics approval was received for all sites.

\section{Participant population}

Children and youth ages 6 to 18 years who presented to the ED with $\mathrm{MH}$ complaints (i.e., primary complaints identified by triage as $\mathrm{MH}$ [psychosocial, behavioural]) were approached for recruitment. Patients were excluded if they 1) did not have the capacity to consent; 2) presented with an overdose requiring medical intervention, or with severe self-harm (e.g., self-harm that required medical treatment), or referred for medical treatment and admitted directly to the hospital; and 3) triaged with Resuscitation (level 1) and Emergent (level 2) levels [REUSN (Resuscitation, Emergent, Semi-urgent, Urgent, Non-urgent) Triage Category; CHEO] or resuscitation or emergent levels (Canadian Triage and Acuity Scale [CTAS] scores 1 and 2, IWK, $\mathrm{SCH}, \mathrm{RAH})$. Patients were eligible once they were stabilized and were approached for the study at the discretion of the ED clinicians. Two disposition pathways were defined based on initial triage: 1) triaged to specialized MH services (SMHS; e.g., crisis worker, psychiatrist, psychologist) directly by the emergency triage nurse or referred by the ED physician; and 
2) seen by the ED physician and then discharged to the community. Direction toward SMHS or the ED physician was determined by a need for medical attention, SMHS availability, and/or site resources.

\section{MEASURES}

A study RA obtained demographic information from the caregiver or patient, identified $\mathrm{MH}$ needs, and recorded discharge recommendations from the medical record (e.g., hospitalization, outpatient services, community services, family physician). At 1 -month post-ED discharge, unaccompanied patients or caregivers who attended the ED were contacted by telephone for a follow-up interview. The interview was designed to elicit descriptions of $\mathrm{MH}$ service experiences (i.e., course of action, services obtained or booked, and community service satisfaction) and on satisfaction with ED care.

\section{Mental health needs}

RAs at each site were trained to observe the clinical assessment of the patient by the SMHS or ED physician and complete the Child and Adolescent Needs and Strengths-Mental Health (CANS-MH 3.0) ${ }^{28}$ sections regarding $\mathrm{MH}$ and risky behaviours. The CANS-MH 3.0 tool integrates information concerning individual needs and strengths of children and youth with $\mathrm{MH}$ challenges. The tool is a communimetric measure, ${ }^{29}$ where individual items use anchors that define levels of action: "0" - no evidence: no action needed; " 1 " watchful waiting/prevention: need should be monitored, or efforts to prevent it from returning or worsening should be initiated; " 2 " - action: intervention required because the need is interfering with individual, family, or community functioning; " 3 " - immediate/ intensive action: need is dangerous or disabling. The CANS-MH 3.0 is reliable at the item level and is unaffected by selecting a subset of target items. ${ }^{30}$ The tool has demonstrated validity, ${ }^{30}$ and total scores have reliably distinguished the level of care received. ${ }^{31}$

\section{Behaviour problems}

Caregivers completed the Child Behavior Checklist $(\mathrm{CBCL})^{32}$ for youth ages 6 to 18 to evaluate behavioural problems and social competencies. A standardized score of $\geq 64$ indicates concern in the wider areas of internalizing (e.g., anxiety, depression, social withdrawal), externalizing (e.g., conduct, aggression, rulebreaking), and total problems, whereas $\geq 70$ indicates areas of clinical concern for specific psychiatric conditions found in the Diagnostic and Statistical Manual for Mental Disorders IV (e.g., anxiety, conduct). Psychometric properties of this instrument are well-established. ${ }^{32}$

\section{Satisfaction}

The Client Satisfaction Questionnaire (CSQ-8@) ${ }^{33}$ was administered at the baseline ED visit and during the 1-month follow-up telephone interview. The CSQ-8 has eight questions designed as a global measure of a patient's satisfaction of their ED visit. Total scores range from 8 to 32; higher scores indicate greater satisfaction with ED services. This tool has established psychometrics and has been used extensively in evaluation studies. ${ }^{34,35}$

\section{Mental health services use}

The first eight questions of the Services for Children and Adolescents-Parent Interview (SCA-PI) ${ }^{36}$ were asked during the follow-up interview to assess number and type of $\mathrm{MH}$ services received within the 1-month post-ED visit. The SCA-PI has good reliability ${ }^{37}$ and face validity with appropriate differences in service reporting. ${ }^{36}$

\section{Recommendations}

Youth or caregivers were asked open-ended questions to elicit ratings of recommendations received during the ED visit. Individuals were asked the following questions: Were you given any recommendations for follow-up care? How were the recommendations given to you? What were the recommendations? Respondents could provide up to four recommendations and rate each as to its usefulness ( $1=$ "not at all" to $4=$ "very"), practicality ( 1 = "definitely not" to $4=$ "very"), openness to the recommendation ( $1=$ "definitely open" to $4=$ "definitely not open" [reverse scored]), whether action was taken related to recommendation $(1=$ yes, $2=$ no), whether the recommendation was obtained $(1=$ yes, $2=$ no), and waitlist status of the recommendation $(1=$ yes, $2=$ no). Four-point scale scores were dichotomized (scales of 1 or 2 were categorized as negative 
ratings [no], and 3 or 4 were categorized as positive ratings [yes]).

\section{STATISTICAL AND QUALITATIVE ANALYSES}

The data were analysed with SPSS version 24.0. ${ }^{38}$ Frequencies described the data by site. An analysis of variance (ANOVA) was conducted to compare the means (Ms) and standard deviations (SDs), which described the differences in participant age among sites. The equality of proportions across sites was assessed by Fisher's exact tests on non-missing data. Crosstabs were used to examine the frequencies of follow-up recommendations between sites and for those who were admitted versus discharged with identified needs in the clinical ranges on the CBCL and CANS-MH 3.0. A paired samples t-test was used to examine change in mean differences of satisfaction over a 1-month period following ED discharge. All tests were two-tailed and a $p<0.05$ was considered statistically significant. Qualitative data on care recommendations were synthesized by finding common recommendation types, and multiple response crosstabs were used.

\section{RESULTS}

\section{Sample demographics}

A total of 373 patients $(M$ age $=15.1$ years; $S D=1.51$; $61 \%$ female) consented to participate (Table 1). Figure 1 illustrates the breakdown of presentations, uptake and attrition rates across sites. At the time of the ED visit, $63.5 \%$ had existing $\mathrm{MH}$ resources, $47.4 \%$ were taking psychotropic medication, and $88.4 \%$ were attending school. One quarter $(24.2 \%)$ were actively involved in the child welfare system. Significant differences among sites were found in the proportion of those involved in the child welfare system, on an assessment order, and those currently attending school (see Table 1).

\section{Clinical demographics}

The top three areas of need requiring action (item score of 2 or 3 on the CANS-MH 3.0) were mood, suicide risk, and parent-child relational problems (Table 2). A higher proportion of psychiatric admissions occurred when needs were identified as requiring immediate action in the areas of psychosis, mood, adjustment to trauma, and suicide risk. Significant differences among actionable ratings were found among sites for a number of symptoms and risky behaviours.

Caregiver CBCL ratings of their child's behaviour (Table 3 ) indicated that $85.5 \%$ were at a level of clinical concern for internalizing behaviour and $60.2 \%$ for externalizing behaviour. The majority of patients were in the clinical range for affect problems, followed by anxiety, somatic, conduct, oppositional, and attention problems. A larger proportion of children were admitted to hospital when CBCL internalizing scores, total scores, and affect were in the clinical range. Those with conduct problems in the clinical range had fewer admissions than those without.

\section{PATIENT MANAGEMENT WITHIN THE ED}

During the ED visit, patients were seen by a crisis worker $(73.2 \% ; n=271 / 370)$, ED physician $(11.4 \%$; $\mathrm{n}=42 / 370)$, ED physician and an $\mathrm{MH}$ professional $(8.9 \% ; n=33 / 370)$, psychiatrist $(4.9 \% ; n=18 / 370)$, psychiatric nurse $(1.4 \% ; n=5 / 370)$, and psychologist $(0.3 \% ; n=1 / 370)$. Acute medical care (e.g., suturing, medical observation, treatment for overdose) and $\mathrm{MH}$ care were required for $21.6 \%(n=80 / 370)$ of patients. A psychiatrist was consulted for $40.9 \%$ of patients $(\mathrm{n}=128 / 313)$ by phone $(20.1 \% ; \mathrm{n}=63 / 313)$ or in person $(20.8 \% ; n=65 / 313)$. Lastly, $19.4 \%(n=72 / 371)$ were admitted to inpatient psychiatric care for stabilization.

\section{FOLLOW-UP SERVICES}

At 1-month follow-up, $84.3 \%$ of patients had received follow-up services, which included any of the following: individual therapy, group therapy, family therapy, school services, overnight treatment, or parent counselling (Table 4). Excluding school and parent counselling, $69.9 \%$ patients received either individual, group, in-home, family, or overnight treatment. The most common follow-up service recommendations were secondary care providers (e.g., psychologist, psychiatrist) followed by home/community care, provision of information, primary care, and tertiary care.

\section{HEALTH CARE SATISFACTION}

At 1-month follow-up, satisfaction scores across sites increased for $30.1 \%(n=46 / 153)$, remained the same for 


\begin{tabular}{|c|c|c|c|c|c|c|}
\hline & $\begin{array}{c}\text { Total } \\
N=373\end{array}$ & $\begin{array}{c}\text { CHEO } \\
n=215\end{array}$ & $\begin{array}{c}\text { IWK } \\
n=104\end{array}$ & $\begin{array}{l}\mathrm{SCH} \\
\mathrm{n}=9\end{array}$ & $\begin{array}{c}\text { RAH } \\
n=45\end{array}$ & $p$-value \\
\hline Age mean (SD) & $15.1(1.5)$ & $15.2(1.4)$ & $15.2(1.8)$ & $14.7(1.0)$ & $14.3(1.3)$ & 0.004 \\
\hline Sex & & & & & & 0.844 \\
\hline Male & $145(38.9)$ & $87(40.5)$ & $40(38.5)$ & $3(33.3)$ & $15(33.3)$ & \\
\hline Female & $228(61.1)$ & $128(59.5)$ & $64(61.5)$ & $6(66.7)$ & $30(66.7)$ & \\
\hline Missing & 0 & 0 & 0 & 0 & 0 & \\
\hline \multicolumn{7}{|l|}{ Assessment order } \\
\hline None & $286(87.7)$ & 184(85.6) & 97 (93.3) & $1(100)$ & $4(66.6)$ & 0.031 \\
\hline Physician & $15(4.6)$ & $14(6.5)$ & 0 & 0 & $1(16.7)$ & \\
\hline Police & $23(7.1)$ & $16(7.4)$ & $6(5.8)$ & 0 & $1(16.7)$ & \\
\hline Justice of the peace & $2(0.6)$ & $1(0.5)$ & $1(0.9)$ & 0 & 0 & \\
\hline Missing & $47(12.6)$ & 0 & 0 & 8 (88.9) & $39(86.7)$ & \\
\hline Current professional resources & & & & & & 0.168 \\
\hline Yes & $233(63.5)$ & $134(62.3)$ & $62(62.0)$ & $4(44.4)$ & $33(76.7)$ & \\
\hline Missing & $6(1.6)$ & 0 & $4(3.8)$ & 0 & $2(4.4)$ & \\
\hline Psychotropic medication & & & & & & 0.455 \\
\hline Yes & $175(47.4)$ & $100(46.7)$ & $51(50.0)$ & $2(22.2)$ & $22(50.0)$ & \\
\hline Missing & $4(1.1)$ & $1(0.5)$ & $2(1.9)$ & 0 & $1(2.2)$ & \\
\hline Child welfare Involvement & & & & & & 0.005 \\
\hline Involved/in care & $89(24.2)$ & $66(30.7)$ & $13(12.5)$ & 0 & $10(25.0)$ & \\
\hline Unknown & $21(5.7)$ & $13(6.0)$ & $7(6.7)$ & 0 & $1(2.5)$ & \\
\hline Missing & $5(1.3)$ & 0 & 0 & 0 & $5(11.1)$ & \\
\hline School Attendance & & & & & & 0.009 \\
\hline Attending & $328(88.4)$ & $198(92.5)$ & $83(79.8)$ & $9(100.0)$ & $38(86.4)$ & \\
\hline Missing & $2(0.5)$ & $1(0.5)$ & 0 & 0 & $1(2.2)$ & \\
\hline
\end{tabular}

$11.1 \%(n=17 / 153)$, and decreased for $58.8 \%(n=90 / 153)$ of youth and caregivers. Overall, ED satisfaction was high $(M=26.5 ; \quad S D=5.5)$ but dropped slightly $(M=24.2$; $\mathrm{SD}=6.5)$ at follow-up (Mdiff $=2.3, \mathrm{SD}=5.0, p<0.001)$. Satisfaction with the ED visit was higher when patients were connected with any recommendation at 1-month post-ED visit $(M=25.9 ; \mathrm{SD}=5.3)$, than those who were $\operatorname{not}(\mathrm{M}=21.2, \mathrm{SD}=7.2), p<0.001, \mathrm{Mdiff}=4.72, p=0.000$, and when patients were admitted $(\mathrm{n}=43 ; \mathrm{M}=27.4 ; \mathrm{SD}=$ 5.0) versus discharged $(n=183 ; M=23.7 ; S D=6.4)$, Mdiff $=3.70, p=0.000$. No significant differences in mean satisfaction were found at 1-month post-ED visit between those already connected to services at the time of the ED visit $(M=23.7 ; S D=6.5)$ and those without services $(\mathrm{M}=25.2 ; \mathrm{SD}=6.0)$.

\section{RECOMMENDATIONS}

Open-ended discharge recommendations were provided and rated by $12.8 \%$ of youth $(n=30 / 234)$ and
$87.2 \%$ of caregivers $(n=204 / 234)$. Recommendations were categorized by level of care (Table 5). Secondary care recommendations were rated as most useful and practical, caregivers and youth were more open to receiving secondary care, and they were more likely to take action and obtain the secondary care recommendation. No significant difference emerged in obtaining any recommended $\mathrm{MH}$ service (excluding information strategies) for those already connected with professional services at the time of the $\mathrm{ED}$ visit $(73.5 \%, \mathrm{n}=75 / 102)$, versus those without $(62.3 \%, \mathrm{n}=43 / 69,95 \%$ confidence interval $[\mathrm{CI}]=-3.7$ to 26.2$)$.

\section{DISCUSSION}

Current literature identifies the ED as the first point of contact for many patients and the $\mathrm{MH}$ system. ${ }^{6-9}$ However, this study demonstrated that the majority (63\%) of patients presenting to the four ED sites were in fact connected to existing resources. These results 


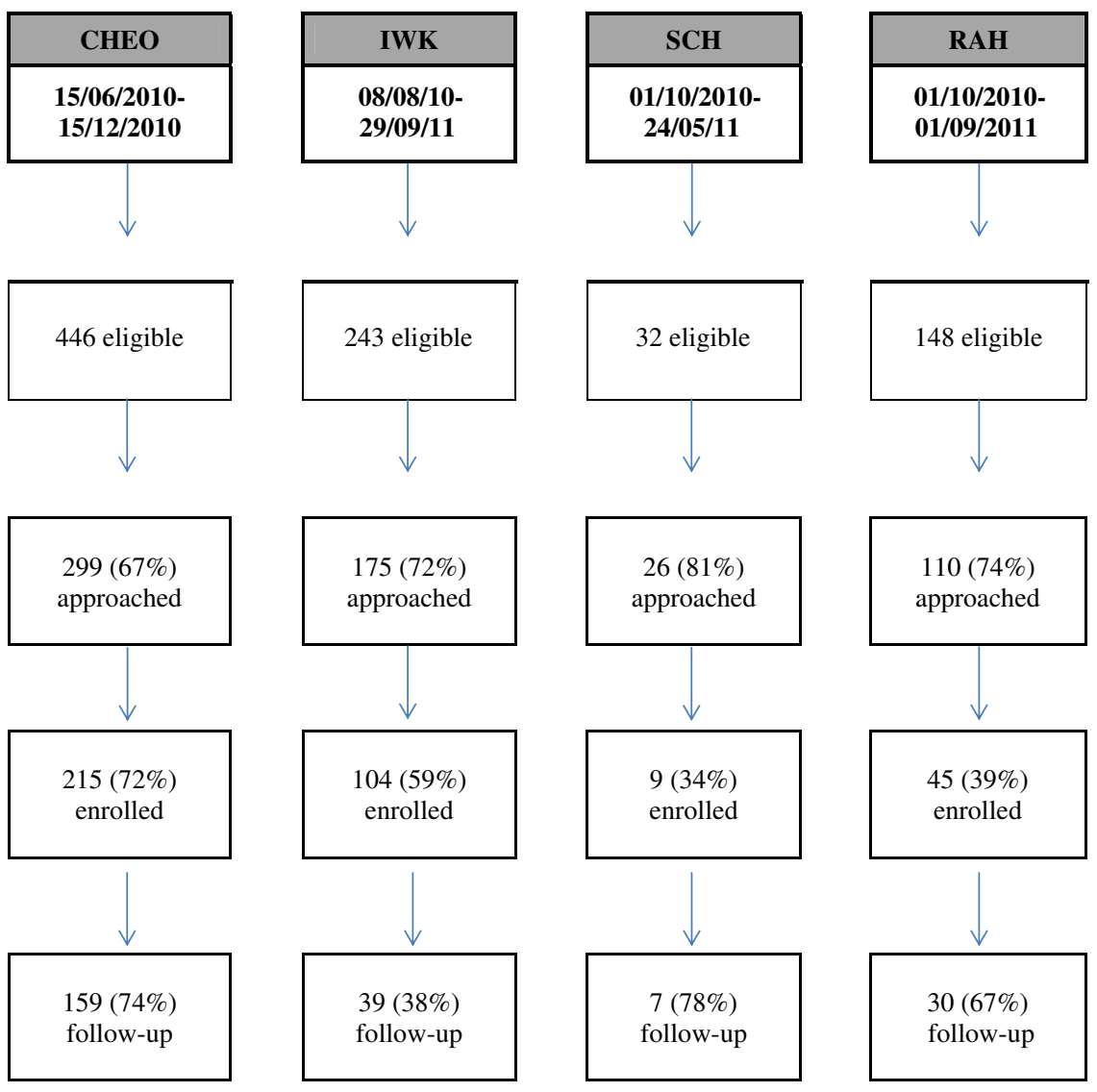

Figure 1. Flow diagram showing participant recruitment and retention rates per site. CHEO=Children's Hospital of Eastern Ontario; IWK = IWK Health Centre; $\mathrm{SCH}=$ Stollery Children's Hospital; RAH = Royal Alexandra Hospital.

are consistent with recent U.S. literature where patients connected to services ranged between $61 \%$ and $83 \% .^{23,39-40}$ Overall, it appears that the ED plays an important role in the continuum of care for pediatric patients and their caregivers, despite accessing other MH services.

Results from this study point to several areas of patient need, including affect and emotional regulation, suicide risk, and parent-child relationship problems. The parent-child relationship has been scarcely investigated or considered in previous ED research ${ }^{41}$ and highlights the need for relational support for families in times of crisis. Given that the ED's role is to provide immediate assistance in an emergency, to address nonurgent patient needs, pathways from the ED to appropriate outpatient and community $\mathrm{MH}$ services should be clearly developed and evaluated. ${ }^{42}$ ED clinicians can play an important role in educating patients and their caregivers about accessing appropriate resources to best meet their $\mathrm{MH}$ needs, including crisis lines, $\mathrm{MH}$ walk-in clinics, and requesting urgent follow-up with existing $\mathrm{MH}$ providers. Tools to quickly and easily access information about local resources should also be available in the ED so that providers can direct patients to appropriate community resources. ${ }^{43}$

Variation between the study EDs, in terms of who uses them and why, points to the necessity of providing a variety of resources to meet variation in population and patient need. Clinical management across sites indicated significant differences for medical care and psychiatric consultations. These differences are consistent with previous Canadian literature ${ }^{11,13}$ and reinforce the need for national policies to guide service development, evaluation, and to promote resource allocation. ${ }^{44}$ Our study adds a unique perspective by including caregiver ratings of child/youth needs, as solely discharge diagnoses at the ED visit and presenting complaints have been examined previously. ${ }^{45}$ Including both caregiver and clinician perspectives as part of standard care can indicate areas of agreement and discrepancy and help the clinician to tailor services and recommendations to meet their patient needs. 


\begin{tabular}{|c|c|c|c|c|c|c|c|c|c|}
\hline & $\begin{array}{c}\text { Total } \\
N=373\end{array}$ & $\begin{array}{l}\text { Admit } \\
n=72\end{array}$ & $\begin{array}{c}\text { Discharge } \\
n=299\end{array}$ & $p$-value & $\begin{array}{c}\text { CHEO } \\
n=215\end{array}$ & $\begin{array}{c}\text { IWK } \\
n=104\end{array}$ & $\begin{array}{l}\mathrm{SCH} \\
\mathrm{n}=9\end{array}$ & $\begin{array}{c}\text { RAH } \\
n=45\end{array}$ & $\begin{array}{c}\text { Site } \\
p \text {-value }\end{array}$ \\
\hline \multicolumn{10}{|l|}{ Symptoms } \\
\hline Psychosis & $28(7.7)$ & $15(21.1)$ & $12(4.1)$ & 0.000 & $11(5.2)$ & $7(6.8)$ & $1(16.7)$ & $9(20.0)$ & 0.009 \\
\hline Missing & $7(1.9)$ & $1(1.4)$ & $6(2.0)$ & & $3(1.4)$ & $1(1.0)$ & $3(33.3)$ & $0(0)$ & \\
\hline Anxiety & $92(25.9)$ & $22(31.4)$ & $70(24.7)$ & 0.287 & $46(22.4)$ & 39 (38.6) & 0 & $7(15.9)$ & 0.004 \\
\hline Missing & $18(4.8)$ & $2(2.8)$ & $16(5.4)$ & & $10(4.7)$ & $3(2.9)$ & $4(44.4)$ & $1(2.2)$ & \\
\hline Mood & $158(43.8)$ & $48(67.6)$ & 109 (37.8) & 0.000 & $88(42.5)$ & $49(48.0)$ & $1(12.5)$ & $20(45.5)$ & 0.258 \\
\hline Missing & $12(3.2)$ & $1(1.4)$ & $11(3.7)$ & & $8(3.7)$ & $2(1.9)$ & $1(11.1)$ & $1(2.2)$ & \\
\hline Attention deficit/impulse control & $68(19.3)$ & $11(15.9)$ & $56(19.9)$ & 0.499 & $40(20.1)$ & $15(14.7)$ & 0 & $13(28.9)$ & 0.157 \\
\hline Missing & $21(5.6)$ & $3(4.2)$ & $18(6.0)$ & & $16(7.4)$ & $2(1.9)$ & $3(33.3)$ & 0 & \\
\hline Oppositional behaviour & $53(14.8)$ & 9 (12.9) & $43(15.0)$ & 0.710 & $26(12.6)$ & $15(14.7)$ & $1(20.0)$ & $11(25.0)$ & 0.166 \\
\hline Missing & $15(4.0)$ & $2(2.8)$ & $13(4.3)$ & & $8(3.7)$ & $2(1.9)$ & $4(44.4)$ & $1(2.2)$ & \\
\hline Conduct behaviour & $27(7.6)$ & $2(2.9)$ & $24(8.5)$ & 0.129 & $8(3.9)$ & $9(8.8)$ & $1(20.0)$ & $9(20.0)$ & 0.002 \\
\hline Missing & $17(4.6)$ & $2(2.8)$ & $15(5.0)$ & & $11(5.1)$ & $2(1.9)$ & $4(44.4)$ & 0 & \\
\hline Emotional control & $86(24.4)$ & $22(31.9)$ & $64(22.7)$ & 0.120 & $46(22.9)$ & $26(25.2)$ & $1(20.0)$ & $13(29.5)$ & 0.821 \\
\hline Missing & $20(5.4)$ & $3(4.2)$ & $17(5.7)$ & & $14(6.5)$ & $1(1.0)$ & $4(44.4)$ & $1(2.2)$ & \\
\hline Parent-child relational problems & $123(34.6)$ & $27(39.7)$ & 95 (33.3) & 0.324 & $83(40.3)$ & $31(30.7)$ & $1(20.0)$ & 8 (18.6) & 0.026 \\
\hline Missing & $18(4.8)$ & $4(5.6)$ & $14(4.7)$ & & $9(4.2)$ & $3(2.9)$ & $4(44.4)$ & $2(4.4)$ & \\
\hline Adjustment to trauma & $76(22.2)$ & $23(33.8)$ & $53(19.4)$ & 0.014 & $46(23.7)$ & $20(19.6)$ & $1(20.0)$ & $9(21.4)$ & 0.885 \\
\hline Missing & $30(8.0)$ & $4(5.6)$ & $26(8.7)$ & & $21(9.8)$ & $2(1.9)$ & $4(44.4)$ & $3(6.7)$ & \\
\hline Eating disturbance & $24(6.8)$ & $4(6.2)$ & $20(7.0)$ & 1.000 & $12(6.0)$ & $8(7.8)$ & 0 & $4(8.9)$ & 0.736 \\
\hline Missing & $20(5.4)$ & $7(9.7)$ & $13(4.3)$ & & $15(7.0)$ & $1(1.0)$ & $4(44.4)$ & 0 & \\
\hline \multicolumn{10}{|l|}{ Risky Behaviours } \\
\hline Suicide risk & $137(37.4)$ & $49(70)$ & $87(29.6)$ & 0.000 & $67(32.1)$ & 37 (35.9) & 8 (88.9) & $25(55.6)$ & 0.000 \\
\hline Missing & $7(1.9)$ & $2(2.8)$ & $5(1.7)$ & & $6(2.8)$ & $1(1.0)$ & 0 & 0 & \\
\hline Self-injuring behaviour & $50(14.3)$ & $6(9.2)$ & $44(15.5)$ & 0.241 & $9(4.6)$ & $31(30.1)$ & 0 & $10(22.2)$ & 0.000 \\
\hline Missing & $23(6.2)$ & $7(9.7)$ & $16(5.4)$ & & $19(8.8)$ & $1(1.0)$ & $3(33.3)$ & 0 & \\
\hline Danger to others & $30(8.3)$ & $9(13)$ & $21(7.2)$ & 0.143 & $13(6.3)$ & $9(8.7)$ & 0 & $8(17.8)$ & 0.102 \\
\hline Missing & $11(2.9)$ & $3(4.2)$ & $8(2.7)$ & & $8(3.7)$ & $1(1.0)$ & $3(33.3)$ & 0 & \\
\hline Elopement & $26(7.3)$ & $3(4.4)$ & $23(8.0)$ & 0.439 & $10(4.9)$ & $8(7.8)$ & 0 & $8(18.2)$ & 0.033 \\
\hline Missing & $16(4.3)$ & $4(5.6)$ & $12(4.0)$ & & $10(4.7)$ & $2(1.9)$ & $3(33.3)$ & $1(2.2)$ & \\
\hline Substance abuse & $62(18.3)$ & $13(19.4)$ & $49(18.1)$ & 0.860 & $36(19.5)$ & $17(16.5)$ & 0 & $9(20.0)$ & 0.767 \\
\hline Missing & $34(9.1)$ & $5(6.9)$ & $29(9.7)$ & & $30(14.0)$ & $1(1.0)$ & $3(33.3)$ & 0 & \\
\hline Social behaviour & $21(6.1)$ & $1(1.5)$ & $20(7.2)$ & 0.091 & $11(5.5)$ & $2(2.0)$ & $1(20.0)$ & $7(17.5)$ & 0.005 \\
\hline Missing & $26(7.0)$ & $4(5.6)$ & $21(7.0)$ & & $14(6.5)$ & $3(2.9)$ & $4(4.44)$ & $5(11.1)$ & \\
\hline Crime/delinquency & $22(6.1)$ & $3(4.3)$ & $18(6.3)$ & 0.777 & $8(3.9)$ & $6(5.8)$ & $3(33.3)$ & $8(17.8)$ & 0.015 \\
\hline Missing & $15(4.0)$ & $3(4.2)$ & $12(4.0)$ & & $11(5.1)$ & $1(1.0)$ & 0 & 0 & \\
\hline Involvement in treatment & $30(8.5)$ & $5(7.4)$ & $23(8.1)$ & 1.000 & $12(5.7)$ & $8(7.8)$ & $1(25.0)$ & $9(25.0)$ & 0.002 \\
\hline Missing & $18(4.8)$ & $4(5.6)$ & $14(4.7)$ & & $3(1.4)$ & $1(1.0)$ & $5(55.6)$ & $8(17.8)$ & \\
\hline
\end{tabular}

Allowing caregivers to voice their concerns and expectations may facilitate identifying precipitating stressors related to the ED presentation and improve familycentred care and intervention. ${ }^{7}$

In this study, the majority of follow-up resources recommended at discharge were secondary care and home/community care. Patients and caregivers perceived these recommendations as most useful, practical, and obtainable as opposed to primary and tertiary care. To our knowledge, this is the only study to comprehensively investigate discharge planning in a nonsuicide specific sample from the perspective of the caregiver. At 1-month follow-up, almost three quarters of patients reported having received some form of MH-specific post-ED care. Slightly lower rates have been reported by recent U.S. studies, where two thirds 
Table 3. Percentage of patients identified with the $\mathrm{CBCL}$ as having mental health concerns in the clinical range by total sample, disposition, and by site, $\mathrm{n}(\%)$

\begin{tabular}{|c|c|c|c|c|c|c|c|c|c|}
\hline Clinical range & $\begin{array}{c}\text { Total } \\
N=249\end{array}$ & $\begin{array}{l}\text { Admit } \\
\mathrm{n}=40\end{array}$ & $\begin{array}{c}\text { Discharge } \\
n=207\end{array}$ & $p$-value & $\begin{array}{l}\mathrm{CHEO} \\
\mathrm{N}=215\end{array}$ & $\begin{array}{c}\text { IWK } \\
N=104\end{array}$ & $\begin{array}{l}\mathrm{SCH} \\
\mathrm{N}=9\end{array}$ & $\begin{array}{c}\mathrm{RAH} \\
\mathrm{N}=45\end{array}$ & $p$-value \\
\hline Internalizing* & 213 (85.5) & 39 (97.5) & 172 (83.1) & 0.014 & 132 (84.1) & 40 (87.0) & 7 (87.5) & $34(89.5)$ & 0.910 \\
\hline Externalizing* & $150(60.2)$ & $22(55.0)$ & $127(61.4)$ & 0.483 & $87(55.4)$ & $29(63.0)$ & $5(62.5)$ & $29(76.3)$ & 0.114 \\
\hline Total* & 205 (82.3) & $38(95.0)$ & 165 (79.7) & 0.022 & 126 (80.3) & 37 (80.4) & $8(100)$ & $34(89.5)$ & 0.376 \\
\hline DSM Affective $^{\dagger}$ & $187(75.1)$ & $35(87.5)$ & $150(72.5)$ & 0.047 & 118 (75.2) & 34 (73.9) & $6(75.0)$ & $29(76.3)$ & 0.992 \\
\hline DSM Anxious $^{\dagger}$ & 121 (48.6) & $24(60.0)$ & $96(46.4)$ & 0.123 & $80(51.0)$ & 19 (41.3) & $2(25.0)$ & $20(52.6)$ & 0.346 \\
\hline DSM Somatic $^{\dagger}$ & 89 (35.7) & $10(25.0)$ & 78 (37.7) & 0.150 & $51(32.5)$ & 15 (32.6) & $3(37.5)$ & $20(52.6)$ & 0.132 \\
\hline DSM Conduct $^{\dagger}$ & 88 (35.3) & $8(20.0)$ & 79 (38.2) & 0.030 & $46(29.3)$ & $18(39.1)$ & $3(37.5)$ & $21(55.3)$ & 0.022 \\
\hline DSM Oppositional $^{\dagger}$ & $84(33.7)$ & $9(22.5)$ & $74(35.7)$ & 0.143 & 47 (29.9) & 16 (34.8) & $2(25.0)$ & $19(50.0)$ & 0.128 \\
\hline DSM Attention $^{\dagger}$ & $53(21.3)$ & $9(22.5)$ & $43(20.8)$ & 0.833 & $30(19.1)$ & 7 (15.2) & 1 (12.5) & $15(39.5)$ & 0.035 \\
\hline
\end{tabular}

Table 4. Follow-up SCA-PI mental health use at 1-month post-ED and follow-up care recommendations by site, $\mathbf{n}(\%)$

\begin{tabular}{|c|c|c|c|c|c|c|}
\hline & $\begin{array}{c}\text { Total } \\
\mathrm{N}=235(69.7)\end{array}$ & $\begin{array}{c}\text { CHEO } \\
n=159(74.4)\end{array}$ & $\begin{array}{c}\text { IWK } \\
n=39(37.5)\end{array}$ & $\begin{array}{c}\mathrm{SCH} \\
\mathrm{n}=7(77.7)\end{array}$ & $\begin{array}{c}\mathrm{RAH} \\
\mathrm{n}=30(64.4)\end{array}$ & $p$-value \\
\hline \multicolumn{7}{|l|}{ Follow-up information } \\
\hline $\begin{array}{l}\text { Receiving any treatment, } \\
\text { including school/parent counselling }\end{array}$ & $193(84.3)$ & $137(86.7)$ & $24(68.8)$ & $6(85.7)$ & $26(89.7)$ & 0.064 \\
\hline Missing & $6(2.5)$ & $2(1.2)$ & $4(10.2)$ & 0 & 0 & \\
\hline Receiving treatment excluding school/parent counselling & $160(69.9)$ & $114(72.2)$ & $21(60.0)$ & $4(57.1)$ & $21(72.4)$ & 0.432 \\
\hline Missing & $6(62.5)$ & $2(1.2)$ & $4(10.2)$ & 0 & 0 & \\
\hline Services provided by & & & & & & 0.015 \\
\hline MH professionals* & $129(85.4)$ & $96(86.5)$ & $12(66.7)$ & $3(100.0)$ & $18(94.7)$ & \\
\hline Health care professionals ${ }^{\dagger}$ & $13(4.6)$ & $12(10.8)$ & $1(5.6)$ & 0 & 0 & \\
\hline Other & $9(6.0)$ & $3(2.7)$ & $5(27.8)$ & 0 & $1(5.3)$ & \\
\hline Missing & $151(64.2)$ & 49 (30.6) & $21(56.8)$ & $4(57.1)$ & $10(34.5)$ & \\
\hline Taking psychotropic medication since ED visit & $122(54.2)$ & $87(55.8)$ & $16(47.1)$ & $4(57.1)$ & $15(53.6)$ & 0.828 \\
\hline Missing & $11(4.7)$ & $4(2.5)$ & $6(15.4)$ & 0 & $1(3.4)$ & \\
\hline Medication monitored & $89(40.1)$ & $68(43.3)$ & $11(36.7)$ & $2(28.6)$ & $8(28.6)$ & 0.463 \\
\hline Missing & $13(5.5)$ & $3(1.9)$ & $9(23.1)$ & 0 & $1(3.4)$ & \\
\hline Overnight stay for treatment & $33(14.8)$ & $23(15.0)$ & $5(14.3)$ & 0 & 5 (17.9) & 0.832 \\
\hline Missing & $12(5.1)$ & 7 (4.4) & $4(10.3)$ & 0 & $1(3.4)$ & \\
\hline \multicolumn{7}{|l|}{ Class of care recommended } \\
\hline Secondary care ${ }^{\ddagger}$ & $125(37.1)$ & $78(32.8)$ & $24(49.0)$ & $3(60)$ & $20(44.4)$ & \\
\hline Home/community care c $^{\S}$ & $106(31.5)$ & $78(32.8)$ & $12(24.5)$ & $2(40)$ & $14(31.1)$ & \\
\hline Information/strategies" & $71(21.1)$ & $55(23.1)$ & $6(12.2)$ & 0 & $10(22.2)$ & \\
\hline Primary care ${ }^{* *}$ & $31(9.2)$ & 26 (10.9) & $4(8.2)$ & 0 & $1(2.2)$ & \\
\hline Tertiary care ${ }^{\dagger \dagger}$ & $4(1.2)$ & $1(0.4)$ & $3(6.1)$ & 0 & 0 & \\
\hline \multicolumn{7}{|c|}{ 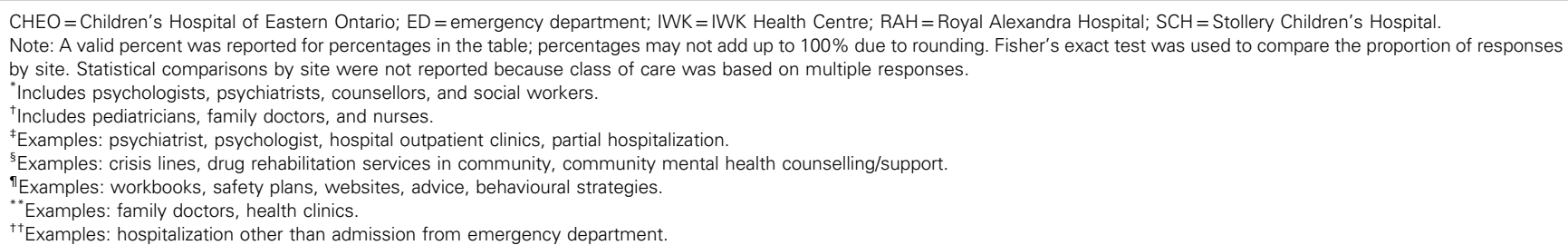 } \\
\hline
\end{tabular}




\begin{tabular}{|c|c|c|c|c|c|}
\hline \multirow[b]{2}{*}{ Recommended service ratings } & \multicolumn{5}{|c|}{ Class of care received } \\
\hline & Secondary ${ }^{\ddagger}$ & $\begin{array}{c}\text { Home/ } \\
\text { community }^{\S}\end{array}$ & $\begin{array}{c}\text { Info/ } \\
\text { strategies" }\end{array}$ & Primary** & Tertiary $^{\dagger+}$ \\
\hline $\begin{array}{l}\text { Useful (yes) } \\
\qquad \begin{array}{l}n=238^{*}(71.9) \\
N=331^{\dagger}\end{array}\end{array}$ & $172(72.3)$ & $162(68.1)$ & $132(55.4)$ & $50(21)$ & $6(2.5)$ \\
\hline $\begin{array}{l}\text { Practical (yes) } \\
\qquad \begin{array}{l}n=261^{*}(78.4) \\
N=333^{\dagger}\end{array}\end{array}$ & $188(72)$ & $176(67.4)$ & $141(54.0)$ & $53(20.3)$ & $5(1.9)$ \\
\hline $\begin{array}{l}\text { Parent open to recommendation } \\
\qquad \begin{array}{l}\mathrm{n}=290^{*}(93.2) \\
\mathrm{N}=331^{\dagger}\end{array}\end{array}$ & $209(72.0)$ & $215(74.1)$ & $142(49.0)$ & $60(20.7)$ & $6(2.1)$ \\
\hline $\begin{array}{l}\text { Youth open to recommendation } \\
\qquad \begin{array}{l}\mathrm{n}=274^{*} \\
\mathrm{~N}=332^{+}\end{array}\end{array}$ & 209 (76.3) & $185(67.5)$ & $143(52.2)$ & $58(21.2)$ & $6(2.2)$ \\
\hline $\begin{array}{l}\text { Action taken } \\
\qquad \begin{array}{l}\mathrm{n}=260^{*} \\
\mathrm{~N}=333^{\dagger}\end{array}\end{array}$ & 199 (76.5) & $164(63.1)$ & $133(51.2)$ & 57 (21.9) & $7(2.7)$ \\
\hline $\begin{array}{l}\text { Obtained follow-up } \\
\qquad \begin{array}{l}n=190^{*}(60.9) \\
N=312^{\dagger}\end{array}\end{array}$ & $154(81.1)$ & $111(58.4)$ & $98(51.2)$ & $39(20.5)$ & $5(2.6)$ \\
\hline $\begin{array}{l}\text { Waitlisted for recommendation } \\
\qquad \begin{array}{l}n=39 * \\
N=281^{\dagger}\end{array}\end{array}$ & $32(82.1)$ & $34(87.2)$ & 15 (38.5) & $9(23.1)$ & $1(2.6)$ \\
\hline $\begin{array}{l}\text { *Number of respondents indicating "Yes" to } \\
{ }^{+} \text {Number of total respondents; percentages a } \\
\text { positive ratings of "Yes." } \\
\text { tExamples: psychiatrist, psychologist, hospit } \\
\text { "Examples: crisis lines, drug rehabilitation se } \\
\text { qExamples: workbooks, safety plans, websi } \\
{ }^{* *} \text { Examples: family physicians, health clinics } \\
{ }^{+\dagger} \text { Examples: hospitalization other than admis }\end{array}$ & $\begin{array}{l}\text { ndation. } \\
\text { y based upon mu } \\
\text { clinics, partial ho } \\
\text { munity, commur } \\
\text { ehavioural stratec } \\
\text { nergency departm }\end{array}$ & $\begin{array}{l}\text { ses indicating "Ye } \\
\text { health counselling/s }\end{array}$ & dividual. Perce & ations of servic & based upon \\
\hline
\end{tabular}

of psychiatric and suicidal youth indicated post-ED connections to community services. ${ }^{23,40}$ It remains unclear in these studies, however, what percentage of pediatric patients who presented to the ED with no prior $\mathrm{MH}$ connections were successful at obtaining services post-ED visit. Frosh and colleagues ${ }^{40}$ have reported that the likelihood of being connected to outpatient services was nearly five times higher at a second ED visit if the youth was already connected at the index visit. This would imply that it may be difficult to initially gain access to services, but, once connected, rates with outpatient providers remain high. It also suggests that the ED may have a useful role at identifying and facilitating initial contact with services in the hopes of improving access to care and decreasing return visits to the ED.

There is little research exploring patient satisfaction with $\mathrm{MH}$ services received in the ED. Overall satisfaction ratings obtained in this study are consistent with existing research indicating a high rate of patient satisfaction. ${ }^{45,46}$ In this study, patients were more satisfied with their ED visit when they received services (e.g., if they were admitted and if they received any recommended service at 1 -month post-ED visit). Previous research has identified several health service variables correlated with satisfaction, including perceived choice in service seeking, expectations about services, duration of treatment, provision of information regarding services, and service site. ${ }^{47,48}$ Despite a statistically significant drop in total satisfaction ratings at 1-month follow-up, the mean drop in ratings was modest and remained in the satisfied range. Changes in scores at follow-up may have been influenced by experiences with obtaining post-ED care, but we did not test this hypothesis.

There are several limitations to this study. There were differences in the percentage of children/youth 
enrolled across study sites and in follow-up rates. The smaller number of children/youth approached at SCH was anticipated, as current practice at the time was to send patients to the RAH, which had in-house pediatric $\mathrm{MH}$ resources. Thus, both sites were included to increase the representativeness of the target population. However, the low participation rates at both the SCH and IWK, and modest participation rates at other sites, introduce the possibility of selection bias. Furthermore, low follow-up rates at IWK may reflect attrition bias; however, this bias was unavoidable due to IWK site research ethics board requirements that limited the number of attempted telephone contacts for each participant. Future studies should also examine satisfaction related to repeat ED visits and the longitudinal $\mathrm{MH}$ care access trajectories past 1 month. Ratings may have suffered from recall bias or social desirability bias. We reduced the risk of social desirability bias by having RAs indicate that they were not part of the ED clinical team and reiterated that survey responses were confidential and would not be shared with the ED staff or physicians.

\section{CONCLUSION}

Pediatric $\mathrm{MH}$ presentations to the ED had significant clinical morbidity. The majority of patients presenting to the ED were connected with services, satisfied with their ED visit, and able to access follow-up care. Clinical trends pointed to high area needs - affect and emotional regulation, suicide risk, and parent-child relations - for ED clinical management. Furthermore, differences in clinical management across study sites point to an important need to standardize clinical approaches. Two areas that can help with clinical management of this patient population include 1) clinical pathways using a set of evidence-based standards to facilitate the management and transition of care from EDs to outpatient and community resources ${ }^{42,49,50}$; and 2) an integrated system linking EDs, primary care, and community $\mathrm{MH}$ agencies. ${ }^{51}$ Future research should investigate the barriers to community care that encourage patients to continue using the $\mathrm{ED}$ as a point of access to MH care.

Acknowledgements: We would like to thank Rebecca Gokiert, Patrick McGrath, Doug Sinclair, and Elizabeth Glennie for their contribution to this study. This work was supported by the Canadian Institutes of Health Research (grant \#103646), The RBC Foundation, and the Children's Hospital of Eastern
Ontario Foundation. Dr. Newton is salary supported as a CIHR New Investigator. Dr. Rosychuk was salary supported as an Alberta Innovates - Health Solutions (AI-HS, Edmonton) Health Scholar during the work.

Competing interests: None declared.

\section{REFERENCES}

1. Simon AE, Schoendorf KC. Emergency department visits for mental health conditions among US children, 20012011. Clin Pediatr (Phila) 2014;53(14):1359-66.

2. Pittsenbarger ZE, Mannix R. Trends in pediatric visits to the emergency department for psychiatric illnesses. Acad Emerg Med 2014;21(1):25-30.

3. Canadian Institute for Health Information. Care for children and youth with mental disorders; 2015. Available at: https:// secure.cihi.ca/free_products/CIHI\%20CYMH\%20Final\% 20for\%20pubs_EN_web.pdf (accessed October 17, 2017).

4. Mapelli E, Black T, Doan Q. Trends in pediatric emergency department utilization for mental health-related visits. 7 Pediatr 2015;167:905-10.

5. Baren JM, Mace SE, Hendry PL, et al. Children's mental health emergencies - Part 1: challenges in care: definition of the problem, barriers to care, screening, advocacy, and resources. Pediatr Emerg Care 2008;24:399-408.

6. Sadka S. Psychiatric emergencies in children and adolescents. New Dir Ment Health Serv 1995;67:65-74.

7. Cloutier P, Kennedy A, Maysenhoelder H, et al. Pediatric mental health concerns in the emergency department: caregiver and youth perceptions and expectations. Pediatr Emerg Care 2010;26:99-106.

8. Gill PJ, Saunders N, Gandhi S, et al. 7 Am Acad Child Adolesc Psychiatry 2017;56(6):475-82.e4.

9. MHASEF Research Team. The mental bealth of children and youth in Ontario: 2017 scorecard. Toronto, ON: Institute for Clinical Evaluative Sciences; 2017.

10. Hamm MP, Osmond M, Curran J, et al. A systematic review of crisis interventions used in the emergency department: recommendations for pediatric care and research. Pediatr Emerg Care 2010;26(12):952-62; doi:10.1097/ PEC.0b013e3181fe9211.

11. Newton AS, Ali S, Hamm MP, et al. Exploring differences in the clinical management of pediatric mental health in the emergency department. Pediatr Emerg Care 2011;27(4): 275-83; doi:10.1097/PEC.0b013e31821314ca.

12. Grupp-Phelan J, Mahajan P, Foltin GL, et al. Referral and resource use patterns for psychiatric-related visits to pediatric emergency departments. Pediatr Emerg Care 2009;25(4): 217-20.

13. Leon SL, Cappelli M, Ali S, et al. The current state of mental health services in Canada's paediatric emergency departments. Paediatr Child Health 2013;118:81-5.

14. Santiago LI, Tunik MG, Foltin GL, et al. Children requiring psychiatric consultation in the pediatric emergency department: epidemiology, resource utilization, and complications. Pediatr Emerg Care 2006;22(2):85-9.

15. Newton AS, Rathee S, Gerwal S, et al. Children's mental health visits to the emergency department: factors affecting 
wait times and length of stay. Emerg Med Int 2014;2014: $1-10$.

16. Christodulu KV, Lichenstein R, Weist M, et al. Psychiatric emergencies in children. Pediatr Emerg Care 2002;18: 268-70.

17. Cloutier P, Kennedy A, Maysenhoelder H, et al. Pediatric mental health concerns in the emergency department: caregiver and youth perceptions and expectations. Pediatr Emerg Care 2010;26:99-106.

18. Newton AS, Ali S, Johnson DW, et al. A 4-year review of pediatric mental health emergencies in Alberta. CFEM 2009;11:447-54.

19. Kennedy A, Cloutier P, Glennie JE, et al. Establishing best practice in pediatric emergency mental health: a prospective study examining clinical characteristics. Pediatr Emerg Care 2009;25:380-6.

20. Cappelli M, Glennie EJ, Cloutier P, et al. Physician management of pediatric mental health patients in the emergency department: assessment, charting, and disposition. Pediatr Emerg Care 2012;28(9):835-41; doi:10.1097/ PEC.0b013e31826764fd.

21 Newton AS, Ali S, Johnson DW, et al. Who comes back? Characteristics and predictors of return to emergency department services for pediatric mental health care. Acad Emerg Med 2010;17(2):177-86; doi:10.1111/j.15532712.2009.00633.x.

22. Stewart SE, Manion IG, Davidson S, et al. Suicidal children and adolescents with first emergency room presentations: predictors of six month outcome. 7 Am Acad Child Adolesc Psychiatry 2001;40:580-7.

23. Sobolewski B, Richey L, Kowatch RA, et al. Mental health follow-up among adolescents with suicidal behaviors after emergency department discharge. Arch Suicide Res 2013; 17(4):323-34

24. Cloutier P, Thibedeau N, Barrowman N, et al. Predictors of repeated visits to a pediatric emergency department crisis intervention program. CFEM 2016;19(2):122-3; doi:10.1017/cem.2016.357.

25. Yu AY, Rosychuk RJ, Newton AS. Clinical acuity of repeat pediatric mental health presentations to the emergency department. 7 Can Acad Child Adolesc Psychiatry 2011;20 (3):208-13.

26. Bridge JA, Marcus SC, Olfson M. Outpatient care of young people after emergency treatment of deliberate self-harm. I Am Acad Child Adolesc Psychiatry 2012;51(2): 213-22.

27. Crandall C, Fullerton-Gleason L, Aguero R, et al. Subsequent suicide mortality among emergency department patients seen for suicidal behaviour. Acad Emerg Med 2006;13:435-42.

28. Lyons JS, Bisnaire L, Greenham S, et al. The child and adolescent needs and strengths (CANS MH 3.0 manual); 2006. Chicago: John Praed Foundation.

29. Lyons JS. Communimetrics: a communication theory of measurement in buman service settings. New York, NY: Springer; 2009.

30. Anderson RL, Lyons JS, Giles DM, et al. Examining the reliability of the child and adolescent needs and strengthsmental health (CANS-MH) scale from two perspectives: a comparison of clinician and research ratings. $\mathcal{F}$ Child Fam Stud 2002;12:279-89.
31. Lyons JS. Redressing the emperor: improving our children's public mental bealth system. Westport, CT: Greenwood Publishing Group; 2004.

32. Achenbach TM, Rescorla LA. The manual for the ASEBA school-age forms \& profiles. Burlington, VT: University of Vermont, Research Center for Children, Youth, and Families; 2001.

33. Attkisson CC, Greenfield TK. The UCSF client satisfaction scales: I. The Client Satisfaction Questionnaire-8. In Maruish $M$ (ed.) The use of psychological testing for treatment planning and outcome assessment, 3rd ed Mahwah, NJ: Lawrence Erlbaum Associates; 2004: 799-811.

34. Attkisson CC, Zwick RJ. The Client Satisfaction Questionnaire: psychometric properties and correlations with service utilization and psychotherapy outcome. Eval Program Plann 1982;5:233-7.

35. LeVois ME, Nguyen TD, Attkisson CC. Artifact in client satisfaction research: experience in community mental health settings. Eval Program Plann 1981;4: 139-50.

36. Jensen PS, Eaton Hoagwood K, Roper M, et al. The services for children and adolescents-parent interview: development and performance characteristics. 7 Am Acad Child Adolesc Psychiatry 2004;43(11):1334-44.

37. Hoagwood K, Jensen PS, Arnold LE, et al. Reliability of the services for children and adolescents-parent interview. I Am Acad Child Adolesc Psychiatry 2004;43(11): $1345-54$.

38. IBM Corp. Released 2016. IBM SPSS Statistics for Windows, Version 24.0. Armonk, NY: IBM Corp.

39. Frosch E, McCulloch J, Yoon Y, et al. Pediatric emergency consultations: prior mental health service use in suicide attempters. I Behav Health Serv Res 2011;38:68-79.

40. Frosch E, DosReis S, Maloney K. Connections to outpatient mental health care of youths with repeat emergency department visits for psychiatric crises. Psychiatr Serv 2011;62:646-9.

41. Leon S, Cloutier P, Polihronis C, et al. Child and adolescent mental health repeat visits to the emergency department: a systematic review. Hosp Pediatr 2017;7:177-86.

42. Jabbour M, Reid S, Polihronis C, et al. Improving mental health care transitions for children and youth: a protocol to implement and evaluate an emergency department clinical pathway. Implement Sci 2016;11:90, doi:10.1186/s13012016-0456-9.

43. Cappelli M, Zemek R, Polihronis C, et al. Evaluating the HEADS-ED: a brief, action oriented, clinically intuitive, pediatric mental health screening tool. Pediatr Emerg Care 2017; epub, doi:10.1097/PEC.0000000000001180.

44. Shatkin JP, Belfer ML. The global absence of child and adolescent mental health policy. Child Adolesc Ment Health 2004;9:104-8.

45. Lehman AF, Zastowny TR. Patient satisfaction with mental health services: a meta analysis to establish norms. Eval Program Plann 1983;6:265-74.

46. Lebow JL. Research assessing consumer satisfaction with mental health treatment: a review of findings. Eval Program Plann 1983;6:211-36. 
47. Garland AF, Aarons GA, Saltzman MD, et al. Correlates of adolescents' satisfaction with mental health services. Ment Health Serv Res 2000;2:127-39.

48. O'Regan C, Ryan M. Patient satisfaction with an emergency department psychiatric service. Int 7 Health Care Qual Assur 2009;22:525-34.

49. Barwick M, Boydell KM, Horning J, et al. Evaluation of Ontario's emergency department clinical pathway for children and youth with mental bealth conditions. Toronto, ON: The Hospital for Sick Children; 2015.
50. ClinicalTrials.gov. Improving transitions in care for children and youth with mental health concerns; 2015. Available at: https://clinicaltrials.gov/ct2/show/NCT02590302 (accessed 20 July 2017).

51. Cappelli M, Leon SL. Paving the path to connected care: strengthening the interface between primary care and communitybased child and youth mental bealth services. Ottawa, ON: Ontario Centre of Excellence for Child and Youth Mental Health; 2017: 1-50. 